\title{
HOSPITAL COSTS OF IMMUNOPREVENTABLE DISEASES IN THE ECONOMICALLY ACTIVE POPULATION IN BRAZIL
}

\author{
Elide Sbardellotto M da Costa $^{1}$, Adriano Hyeda ${ }^{1}$, and Eliane Cesario Pereira Maluf ${ }^{1}$ \\ ${ }^{1}$ Federal University of Paraná Clinics Hospital
}

March 31, 2021

\begin{abstract}
Immunopreventable diseases are a public health reality in Brazil and worldwide. Objectives and Methods: A population, observational, descriptive, retrospective study was conducted with secondary information from DATASUS to discriminate the hospitalizations associated with immunopreventable diseases in Brazil and their care costs, within the Scope of the SUS, between 2008 and 2018, in the economically active population (20 to 59 years). Results: It was analyzed for 457,479 hospitalizations, total of 127,746 hospitalizations ( $27.92 \%$ of all hospitalizations) were observed for immunopreventable diseases in the adult population, totaled $\mathrm{R} \$ 115,682,097.54$ (29.72\% of the total values. The trend analysis of the time series of hospitalizations in this population showed a stationary trend. Conclusions: It were identified an opportunity of increasing the immunization coverage in the workforce population, for avoided hospitalizations and their costs for the health system.
\end{abstract}

\section{Hosted file}

Doenca imunoprevenivel 20-59anos 290321 INGLES.pdf available at https://authorea.com/users/ 405017/articles/516088-hospital-costs-of-immunopreventable-diseases-in-the-economicallyactive-population-in-brazil 